This is a post-print version of the paper:

Hofmann, V. \& Müller, C. (2018). Avoiding antisocial behavior among adolescents: The positive influence of classmates' prosocial behavior. Journal of Adolescence, 68, 136145.

https://doi.org/10.1016/j.adolescence.2018.07.013

https://www.sciencedirect.com/science/article/pii/S0140197118301489 


\title{
Avoiding Antisocial Behavior among Adolescents: The Positive Influence of Classmates' Prosocial Behavior
}

\begin{abstract}
Introduction. Prior research has shown that classmates' behavior serves as a descriptive norm for adolescents' individual behavior. While earlier studies primarily focused on negative peer influence, classmates' prosocial behavior might be associated with positive individual development. We hypothesized more classroom-level prosocial behavior predicts a lower likelihood of future antisocial behavior of individual students over and above the effect of classmates' antisocial behavior. We further assumed this effect is mediated by adolescents' attitudes toward antisocial behavior.

Methods. To test our hypotheses, we used three data collection points from a longitudinal study among lower secondary school students in Switzerland $(N=864$; mean age at T1: 13.81 years; male gender: 52\%). Participants completed self-reported assessments on prosocial behavior, antisocial behavior, and antisocial attitudes. Data were analyzed using multilevel models.

Results. Results indicated higher levels of prosocial behavior among classmates predict lower levels of individual students' future antisocial behavior. However, the effect of classmates' prosocial behavior was not mediated by individual attitudes toward antisocial behavior.

Conclusions. While in the context of antisocial behavior the peer group is often assumed a risk, our results indicate that school peers can also exert positive influence. Hereby our finding of an effect of prosocial peer norms over and above antisocial peer norms suggests that building up prosocial behaviors in the classroom may be a promising approach for the prevention of antisocial behavior.
\end{abstract}

Keywords: antisocial, prosocial, adolescents, behavior, attitudes, classmates. 
Antisocial behavior is a major concern in adolescent development. It is characterized by recurrent violations of socially prescribed norms in different contexts, such as in public, at home, or in school (Simcha-Fagan, Langner, Gersten, \& Eisenberg, 1975). Antisocial behavior includes "physical or verbal abuse of a person, damage to or theft of property, or victimless clandestine juvenile behaviors such as truancy and drug or alcohol use" (Loeber, 1985, p. 77). Adolescents differ strongly in the degree of antisocial behavior they exhibit. While high levels of such behavior are a main risk factor for longterm criminal involvement (e.g., Monahan, Steinberg, Cauffman, \& Mulvey, 2009), even less frequent antisocial acts can harm other people, such as peers and family. For adolescents themselves, exhibiting antisocial behavior increases the risk of failing in school, developing other psychological disorders, and being socially rejected (Quinn \& Poirier, 2004). To counteract these outcomes, it is important to identify factors that may help prevent or reduce antisocial behavior.

One important factor related to adolescents' antisocial behavior is negative peer influence. Negative peer influence can occur within various types of social networks, such as dyadic friendships, cliques, or classrooms (for an overview, see Dishion \& Tipsord, 2011). While there is ample evidence negative peer influence has an unfavorable impact on antisocial behavior, a predominantly negative view of peer influence has also been criticized (Brown, Bakken, Ameringer, \& Mahon, 2008). Nevertheless, to date limited empirical knowledge exists regarding the potential effects of positive peer influence on antisocial behavior and its underlying processes. Thus, we investigated whether higher levels of peer prosocial behavior contribute to less future antisocial behavior in individual adolescents. Prosocial behavior can be understood as a "broad range of actions intended to benefit one or more people other than oneself — behaviors such as helping, comforting, sharing, and cooperating” (Batson \& Powell, 2003, p. 463). As a potential underlying mechanism, we examined whether individual attitudes toward antisocial behavior mediate the effect of peer prosocial behavior on individual antisocial behavior. Concerning peer group, we focused on classmates in lower secondary school. 


\section{Classmates' Behavior and Students' Individual Behavior}

Adolescents interact with their classmates and other friends from school on a daily basis, and these social networks from school often carry over into spare time (Kiesner, Poulin, \& Nicotra, 2003). In class, students may not only be influenced by the words and actions of their close friends or dominant students, but also by behaviors observed in the entire classroom (Dijkstra, Lindenberg, \&Veenstra, 2008; Powers \& Bierman, 2013; Vitaro, Brendgen, \& Tremblay, 2000). For example, Dijkstra and colleagues (2008) found that bullying by popular students was related to increased acceptance of bullying within the classroom and hence decreased rejection of individuals who engaged in bullying.

The current study is interested in behavioral influence among all classmates within a classroom (for an overview, see Anonymous Authors, 2016). This focus on all classmates allows for insights into the effects of an involuntary, non-self-selected peer group, and enables investigation of peer influence effects that are not confounded with selection effects (Juvonen \& Galván, 2008). In addition, understanding the role of the whole classroom may provide future perspectives for classroom-wide interventions.

The behavior of all group members (i.e., the classroom mean of antisocial behavior) is often referred to as a descriptive norm, which represents typical behavior in a group (Cialdini, Kallgren, \& Reno, 1991). According to social learning theories, different mechanisms may underlie a direct effect of descriptive norms on individual student behavior. These processes can include, for example, imitating, reinforcing, or sanctioning specific behaviors (Akers, 2009; Bandura \& Walters, 1963; Burgess \& Akers, 1966; Cohen, 1964; Shaffer, 1983). It can be assumed that certain salient behaviors (i.e., those related to popularity; Jonkmann, Trautwein, \& Lüdtke, 2009) will be reinforced by peers whereas others will be negatively sanctioned.

Empirical evidence suggests an effect of descriptive norms on individual future behavior within the same behavioral domain. Regarding antisocial behaviors, several studies found that more positive descriptive classroom norms toward such behaviors are directly related to more individual antisocial behavior in the future (e.g., Barth, Dunlap, Dane, Lochman, \& Wells, 2004; Megens \& Weerman, 2011; Mercer, McMillen, \& DeRosier, 2009). Mercer and colleagues' longitudinal study, for example, investigated the 
influence of classroom-level aggressive behavior on individual aggressive behavior. The authors found an increase in individual aggression when classroom-level aggression was high. In terms of prosocial behaviors, classmates' prosocial behavior was found to be associated with more future prosocial behavior among individual students (Hoglund \& Leadbeater, 2004). However, it is less clear if cross-behavioral influence exists: Does prosocial peer behavior affect students' future antisocial behavior? Investigating this question may shed light on whether individual antisocial behaviors can potentially be reduced by promoting prosocial behavior at the classroom level.

\section{Effects of Classmates' Prosocial Behavior on Individual Antisocial Behavior}

Prosocial and antisocial behaviors are assumed to represent different yet related constructs, instead of representing two extremes of one scale (Veenstra, 2006). They are

typically considered to be contrary to each other. For example, if a student hits a classmate in a highly prosocial classroom, this action is perceived as going against the prosocial norm. Supporting this conceptual relationship between the two constructs, studies have shown that antisocial and prosocial behaviors/attitudes are negatively correlated (e.g., Boxer, Tisak, \& Goldstein, 2004). From an empirical perspective, it would thus be reasonable to expect that in a context of more prosocial peer behavior, students will have a lower likelihood of developing antisocial behaviors.

Some studies found evidence that classroom prosocial norms are related to less antisocial behavior among individual students. For example, Henry and Chan (2010) followed students from Grade 6 to Grade 8 and found classroom-level norms regarding nonviolent problem solving were negatively related to future occurrence of individual aggressive behavior and to positive attitudes toward aggression. Using a similar study design, Henry, Farrell, Schoeny, Tolan, and Dymnicki (2011) reported the same effects when considering the influence of school-level norms. While these studies provide important initial results, it must be noted they measured injunctive norms, which refer to peers' attitudes (Cialdini et al., 1991). As attitudes and behavior may differ, the role of the classmates' actual prosocial behavior remains unknown. It is also unclear whether prosocial peer influence is related not only to aggression but also to a broader range of antisocial 
behaviors. In addition, to our knowledge, no study has yet sought to identify the psychological mechanisms through which classmates' prosocial behavior influences individual students' antisocial behavior. A pure imitation process is unlikely, as students can only imitate behavior in the same behavioral domain (e.g., imitation of peers' antisocial behavior leads to individual antisocial behavior). It is thus possible that classmates' prosocial behavior is related to individual antisocial attitudes, which in turn affect future behavior. Hence, peers' prosocial behavior may indirectly influence adolescents' antisocial behavior.

\section{Attitudes as a Mediator Between Classmates' and Individual Behavior}

Attitudes can be defined as "a psychological tendency that is expressed by evaluating a particular entity with some degree of favor or disfavor" (Eagly \& Chaiken, 1993, p. 1). While this general definition is widely accepted, there are contradictory opinions concerning what kinds of evaluations are regarded as attitudes (for an overview, see Aronson, Wilson, \& Akert, 2014). Fishbein and Ajzen (1975) posit attitudes are emotional rather than cognitive evaluations, and thus should be assessed by measuring how a person feels about a certain behavior (not what is known about the behavior). This approach may be specifically useful for reducing social desirability bias when measuring antisocial attitudes. For example, an adolescent may know making fun of a teacher is not accepted at school yet still consider it "cool" to do so (see also Anonymous Authors, 2013). Although not all problems related to antisocial attitudes measurement can be solved using this approach, measuring how "cool" adolescents find antisocial behavior may be less sensitive to social desirability effects than assessing how acceptable they find such behaviors.

Regarding a mediation effect of attitudes, the first path we suggest is that classmates' prosocial behavior influences individual attitudes toward antisocial behavior. This expectation is based on social learning theories, which predict that individual attitudes are affected by peer group behavior (Burgess \& Akers, 1966; Thornberry, 1987). For example, Thornberry's (1987) interactional theory of delinquency suggests that being surrounded by peers who exhibit antisocial behavior is related to more favorable individual 
attitudes toward antisocial behaviors. When considering antisocial and prosocial behaviors as two contrary constructs, it may be expected that more prosocial peer behavior (i.e., prosocial descriptive classroom norms) will contribute to less favorable individual attitudes toward antisocial behavior.

The second path of the mediation process relates to our expectation that individual antisocial attitudes influence individual antisocial behavior. This assumption refers to models that describe the role of attitudes in predicting behavior, such as the theory of planned behavior (Ajzen, 1985, 1991). According to the theory of planned behavior, attitudes serve as a predisposition for behavioral intentions, which are in turn related to actual behavior. In addition, empirical evidence suggests antisocial behavior is predicted by positive attitudes toward such behavior (e.g., Cohn, Bucolo, Rebellon, \& Van Gundy, 2010; Halgunseth, Perkins, Lippold, \& Nix, 2013).

In summary, we expected the more prosocial behavior is exhibited among classmates, the less likely it is students will show individual antisocial behavior in the future (Hypothesis 1). We further assumed a mediating effect of individual attitudes. That is to say, we expected more prosocial behavior in the classroom is associated with less favorable attitudes toward antisocial behavior of individual students, and those attitudes are then related to a lower likelihood individual students exhibit antisocial behavior (Hypothesis 2).

\section{The Current Study}

The study at hand used a non-experimental longitudinal design with three measurements across Grades 7 to 9. This design allowed us to control for the temporal order of events (i.e., to rule out bidirectional pathways). To test our hypotheses, we followed the recommendations of Rose, Holmbeck, Coakley, and Franks, (2004) and Vanhove (2015) for analyzing change and mediation in a longitudinal design. The influence of classmates' prosocial behavior on decreased likelihood of individual antisocial behavior (Hypothesis 1) was analyzed by predicting individual antisocial behavior at T3 by classmates' behavior at T1, controlling for T1 individual behavior. With regard to Hypothesis 2, we tested whether classmates' prosocial behavior at T1 predicts antisocial 
attitudes at T2, and if decreased likelihood of antisocial behavior between T1 and T3 is predicted by individual attitudes.

Prosocial and antisocial behaviors can be considered two distinctive behavioral domains, thus they may exert separate influence on individual students' behavior. In order to test the specificity of the effect of classmates' prosocial behavior, we controlled for classmates' antisocial behavior at T1 in our models predicting individual attitudes and behaviors. In case of a significant effect, the influence of classmates' prosocial behavior can then be interpreted as being over and above the effect of classmates' antisocial behavior.

Given the mixed literature on the role of gender in peer influence on antisocial behavior, we also controlled for gender in our analyses. While much research suggests that boys exhibit more antisocial behavior than girls (e.g., Mears, Ploeger, \& Warr, 1998) other authors have reported girls exhibit more externalizing behavior, at least in at-risk populations (e.g., Urben et al., 2016). Similarly, some studies found greater susceptibility to peer influence among boys (e.g., Mears et al., 1998; Parsai, Voisine, \& Marsiglia, 2009) while others found greater susceptibility among girls (e.g., Mercken, Snijders, Steglich, Vertiainen, \& De Vries, 2010; Schulenberg et al., 1999). Hence, to omit biased effects due to gender differences, students' gender has been controlled for in all statistical models.

\section{Methods}

\section{Participants}

We used data from the longitudinal XX-study (Anonymous Authors), which was conducted in the bilingual (German and French) canton of XX in Switzerland. Due to a close collaboration between the university and the local governmental education department in this study, all lower secondary schools and all classrooms from the German speaking part of XX participated in the study. Hence, we followed a nearly complete cohort of students who transitioned to secondary school in 2011 from Grade 7 to Grade 9 (all student and school recruitment occurred before T1). This investigation used data collected at the end of Grade 7, Grade 8, and Grade 9. The sample's mean age was 13.81 years ( $S D=$ 0.49 ) at T1, with $52 \%$ male participants. The sample included students from 8 schools and 
55 classrooms who participated at least once during the study $(N=864)$. With support from school authorities, participation rates at different measurement points were high (T1: 96.3\% out of $N=821$; T2: $94.2 \%$ out of $N=831$; T3: $81.5 \%$ out of $N=812$ ). Mean classroom participation rates across assessment points ranged from $79.01 \%$ to $96.33 \%$. Total student numbers differed slightly across measurement points, as students moved into or away from the region and thus changed schools. Individual students were followed across time when they changed classrooms within a school and when they changed schools within the canton. They were not followed when they changed to a school in a different canton. Across all time points, 595 (68.87\%) out of 864 students participated in all three measurement points and $762(88.19 \%)$ participated in at least at two of the three measurement points.

Most students came from rural regions, as only one school was located in a town with more than 10,000 inhabitants. To approximate immigration background, participants were asked to report whether they owned a foreign passport (possibly along with a Swiss passport); $23 \%$ of the sample owned a foreign passport. Socioeconomic status was measured using the International Socioeconomic Index of Occupational Status (ISEI; Ganzeboom \& Treiman, 1996), using the more highly rated occupation of the parents. The ISEI converts occupation into income and then categorizes income in a scoring system that ranges from 16 (lowest socioeconomic status) to 90 (highest socioeconomic status). The average ISEI in the sample was 49.23 ( $S D=16.04)$, which corresponds to the national Swiss average (Vellacott, Hollenweger, Nicolet, \& Wolter, 2003). Regarding academic track, students were grouped according to achievement criteria into: an advanced track ( $N=$ $238 ; 28.7 \%)$, a general track $(N=344 ; 41.5 \%)$, a basic track $(N=195 ; 23.6 \%)$, and special educational classrooms for students with learning difficulties $(N=51 ; 6.2 \%)$. Students remained in tracked classrooms for all lessons and were always exposed to the same peer environment during instruction. Each classroom had one main teacher but for certain subjects, students also attended lessons taught by other teachers. 


\section{Measures}

Individual antisocial behavior. To assess the dependent variable, the "antisocial behavior" subscale of the German version of the Reynolds Adolescent Adjustment Screening Inventory (RAASI; Hampel \& Petermann, 2005; Reynolds, 2001) was used. To control for changes over time, antisocial behavior was assessed twice (at T1 and T3). The scale had eight items that correspond to the definition of antisocial behavior (Loeber, 1985), whose scores were summed. This included questions about behaviors such as consuming drugs or alcohol, staying out without parental knowledge (or longer than declared), violating school or home rules, performing bad activities, experiencing problems at home or in school, not doing homework, and breaking the law. The actual wording was, for example, "in the last six months, I did things that were against the law." Participants rated behavior frequency on a 3 -point scale $(0=$ never or almost never, $1=$ sometimes, and 2 = almost always). The possible score range was 0 to 16 .

The German version of the scale has been psychometrically evaluated and found to be reliable and valid. The RAASI subscale of "antisocial behavior" has correlated significantly in the expected directions (between $r=.53$ and $r=.62$ ) with similar subscales of the Youth Self-Report version of the Child Behavior Checklist (Achenbach, 1991; for additional detail see Hampel \& Petermann, 2005). In this study, the internal consistency was $\alpha=.83$ at $\mathrm{T} 1$ and $\alpha=.77$ at T3.

Classmates' antisocial behavior. Classmates' antisocial behavior was calculated for each student by averaging all students' scores in a class, excluding the person's own score (see Henry et al., 2000). Hence, each student had a context score of his or her classmates' mean level of antisocial behavior.

Classmates' prosocial behavior. Classmates' prosocial behavior was calculated in the same way as classmates' antisocial behavior so that each student had a context score of his or her classmates' mean level of prosocial behavior. Prosocial behavior was measured at T1 by five items of the subscale "prosocial behavior" of the Strengths and Difficulties Questionnaire (SDQ; Goodman, Meltzer, \& Bailey, 1998) “prosocial behavior” subscale. The German self-report version of the questionnaire was found at www.sdqinfo.org. Along with the definition of prosocial behavior by Batson and Powell (2003), adolescents were 
asked if they: are kind to other people and care about their feelings; share things with others; are helpful if someone is hurt, upset, or feeling ill; are kind to younger children; and offer to help. Participants rated along a 3 -point-scale $(0=$ not true, $1=$ somewhat true, $2=$ certainly true). Scores from each item were summed (summed score range 0 to 10).

The evaluation of the German version of the SDQ found comparability to the English version (Klasen, Woerner, Rothenberger, \& Goodman, 2003). The internal consistency was $\alpha=.77$ in the current study.

Antisocial attitudes. The mediator variable "antisocial attitudes" was measured at T2 using the self-reported version of the Fribourg Self- and Peer-Report Scales - Antisocial Behavior (Müller, 2013). Students used a 5-point-scale $(0=$ uncool, $4=\mathrm{cool})$ to evaluate their approval of specific behaviors. The statements rated followed the format, "If people of my age do something like [the behavior of interest], I find it ..." The concept of coolness was used as a more affect-oriented approach to assess attitudes versus the question about something being considered right or wrong. The scale assessed attitudes toward 20 antisocial behaviors (e.g., hitting, pushing around, threatening, annoying, insulting others, consuming alcohol or drugs, dodging fare payment, skipping school, destroying others' belongings, shaking somebody down, engaging in theft, or public vandalism). Items were combined to a scale mean (possible range 0 to 4 ). Items were chosen based on an exploratory factor analysis, and have been found to be psychometrically adequate in terms of validity and reliability (for more detail see Müller, 2013). In the current study, we found an internal consistency of $\alpha=.95$.

Gender. Students self-identified as male or female.

\section{Procedure}

A letter was sent to students and parents by the local governmental education department and university to inform them about the study and the voluntary nature of participation. The letter emphasized students would never have to provide names and only the research team would use the data. Students completed a questionnaire using mobile blinds to allow for optimally independent answering. Trained research assistants introduced the questionnaires in detail. To follow individual trajectories across data collection without 
having access to participants' names, individual codes were used for stable student characteristics, such as school number, classroom number, gender, nationalities, number of middle names, dominant writing hand, having older siblings, specific language(s) spoken at home, and repeating a class in primary school. This procedure and additional double-checks by the research team enabled unambiguous matching of all students across measurement points.

\section{Statistical Analyses}

In order to provide information about the frequencies and distributions of the variables and the single items of behavior, we first calculated descriptive statistics. We next determined correlations between the variables to indicate the strength of their relationships to each other. To obtain appropriate results for hypotheses tests, the hierarchical data structure was considered (Raudenbush \& Bryk, 2002). Individual student measures were not independent, as they were nested within classrooms. That is, students within the same classroom are likely more similar relative to students from other classrooms. As this might lead to biased results, multilevel models controlling for clustering within higher-level units (i.e., students within classrooms) were estimated. Analyses were conducted using Mplus version 7.4 (Muthén \& Muthén, 2015), which accounts for missing values of unbalanced data by using a full information maximum likelihood estimation. In addition, we used robust standard error estimations. Among participating students, there was only a small amount of missing information (between $0 \%$ and 2.9\%) on the variables used in the statistical models.

To test Hypothesis 1, the total effect of classmates' prosocial behavior at T1 on individual antisocial behavior at T3 was estimated, controlling for individual and classmates' antisocial behavior at T1. Hypothesis 2 assumed this effect was mediated by individual attitudes toward antisocial behavior. According to recent simulation studies (e.g., Kenny \& Judd, 2014; Rucker, Preacher, Tormala, \& Petty, 2011), mediation analyses should focus on the interpretation of indirect effects. As the statistical power of total, direct, and indirect effects cannot be compared, it is not advisable to test if there is a total or a partial mediation effect, and testing should focus on whether a significant indirect effect 
could be found. The assumptions for testing an indirect effect are fulfilled when there is a significant effect of the predictor on the mediator, and a significant effect of the mediator on the dependent variable. In case these assumptions are met, the indirect effect can be tested using a Sobel test, which is implemented in Mplus.

\section{Results}

Descriptive statistics. Table 1 presents the incidences and ranges of the individual items of the antisocial and prosocial behavior measures. The mean score for the antisocial behavior items are quite low (between 0.12 and 0.37 on a scale from 0 to 2 ), indicating those behaviors were relatively uncommon among participants. The highest mean was for the item "not having learned or not having done the homework" and the lowest mean was for "alcohol and drug consumption". In contrast, there were high scores for prosocial behavior items (between 1.39 and 1.69 on a scale from 0 to 2). The lowest rated item was "offering to help people without being asked" and the highest rated was "being kind to younger children." 
Table 1

Incidence of antisocial and prosocial behaviors at T1 (sorted by increasing means)

\begin{tabular}{|c|c|c|c|}
\hline & $M$ & $S D$ & $\begin{array}{r}\text { Observed } \\
\text { Range }^{\mathrm{a}} \\
\end{array}$ \\
\hline \multicolumn{4}{|l|}{ Antisocial behavior } \\
\hline Alcohol and drug consumption & 0.12 & 0.39 & $0-2$ \\
\hline Staying away from home without the parents' knowledge & 0.14 & 0.39 & $0-2$ \\
\hline Breaking the law & 0.15 & 0.41 & $0-2$ \\
\hline Performing bad activities & 0.15 & 0.41 & $0-2$ \\
\hline Getting in trouble at home or at school & 0.26 & 0.51 & $0-2$ \\
\hline Staying away from home longer than declared & 0.26 & 0.52 & $0-2$ \\
\hline Violating school or home rules & 0.30 & 0.53 & $0-2$ \\
\hline Not having learned or not having done the homework & 0.37 & 0.58 & $0-2$ \\
\hline \multicolumn{4}{|l|}{ Prosocial behavior } \\
\hline Offering to help people without being asked & 1.39 & 0.60 & $0-2$ \\
\hline Sharing things with others & 1.56 & 0.59 & $0-2$ \\
\hline Being kind to other people & 1.57 & 0.57 & $0-2$ \\
\hline Offering help when someone is hurt, upset, or feeling ill & 1.58 & 0.54 & $0-2$ \\
\hline Being kind to younger children & 1.69 & 0.52 & $0-2$ \\
\hline
\end{tabular}

${ }^{a}$ Antisocial behavior: from $0=$ never or almost never to $2=$ almost always; prosocial behavior: from $0=$ not true to $2=$ certainly true.

Table 2 presents descriptive characteristics for all variables used for subsequent hypotheses tests. The sample mean of antisocial behavior was 1.75 at the end of Grade 7 (T1) and 2.39 at the end of Grade 9 (T3), whereas the possible scale maximum was 16. Nevertheless, the standard deviations were quite large (T1: 2.54; T3: 2.52) compared to the mean and the range of observed values included the possible scale maximum at T1.

Performing a dependent sample t-test indicated a significant increase in antisocial behavior from the first to second measurement $(t(598)=-7.849, p<.01)$. In accordance with the results of the single items, the descriptive results of classmates' prosocial behavior revealed relatively high scores. The sample mean was 7.77 on a scale from 0 to 10 (with 10 as the highest possible score) and the range was 5.80 to 9.33 . The sample mean of classmates' 
antisocial behavior was 1.77 and hence quite similar to individual antisocial behavior. However, as the scores referred to classroom means minus individual scores, there was less variation in the data. Finally, the sample mean of antisocial attitudes was 0.49 and the observed range was 0 to 4 , which corresponds to the possible scale range.

Table 2

Descriptive Statistics

\begin{tabular}{lrrrr}
\hline & $M$ & $S D$ & Observed Range & $\%$ \\
\hline Individual antisocial behavior T1 & 1.75 & 2.54 & $0.00-16.00$ \\
Individual antisocial behavior T3 & 2.39 & 2.52 & $0.00-14.00$ \\
Classmates' prosocial behavior T1 & 7.77 & 0.61 & $5.80-9.33$ \\
Classmates' antisocial behavior T1 & 1.77 & 0.89 & $0.23-4.83$ \\
Individual antisocial attitudes T2 & 0.49 & 0.61 & $0.00-4.00$ & \\
Male gender & & & & 52 \\
\hline
\end{tabular}

Bivariate correlations between all variables were calculated to obtain insights into the relationships between the key variables (Table 3). A high correlation $(r=.51)$ was found between the two measurements of individual antisocial behavior at T1 (end of Grade 7) and T3 (end of Grade 9). Only small negative correlations were found between classmates' prosocial behavior and individual antisocial behavior and attitudes $(r=-.11$ to $r$ $=-.12)$. Small positive correlations were found regarding classmates' antisocial behavior $(r$ $=.08$ to $r=.17$ ). There was a high negative correlation of $r=-.50$ between classmates' prosocial and antisocial behaviors. This finding supports our theoretical assumption that the two behavioral domains are negatively related to each other but still represent two distinctive constructs. Furthermore, individual antisocial attitudes were moderately related to individual antisocial behavior $(r=.37$ to $r=.38)$. There were small correlations between the control variable "gender" and other individual variables $(r=.14$ to $r=.29)$ but no relevant correlation of gender with classmates' prosocial and antisocial behavior $(r=.02$ to $r=.06)$. All effects were significant at the 5\% level, except for the correlations between gender and classmates' prosocial and antisocial behavior. 
Table 3

Correlations

\begin{tabular}{|c|c|c|c|c|c|c|}
\hline & 1 & 2 & 3 & 4 & 5 & 6 \\
\hline 1. Individual antisocial behavior $\mathrm{T} 1$ & - & $.51^{* *}$ & $-.11^{* * *}$ & $.17^{* *}$ & $.38^{* * *}$ & $.14^{* * *}$ \\
\hline 2. Individual antisocial behavior T3 & & - & $-.11^{* *}$ & $.11^{* *}$ & $.37^{* *}$ & $.20^{* *}$ \\
\hline 3. Classmates' prosocial behavior T1 & & & - & $-.50^{* *}$ & $-.12^{* *}$ & .06 \\
\hline 4. Classmates' antisocial behavior T1 & & & & - & $.08^{*}$ & .02 \\
\hline 5. Individual antisocial attitudes $\mathrm{T} 2$ & & & & & - & $.20^{* *}$ \\
\hline 6. Male gender & & & & & & - \\
\hline
\end{tabular}

Hypothesis 1. This hypothesis sought to determine whether classmates' prosocial behavior is related to a lower likelihood of future antisocial behavior of individual students. We tested whether antisocial behavior at T3 was predicted by classmates' prosocial behavior at T1, controlling for individual and classmates' antisocial behavior at T1 and gender (see Table 4).

Results showed a significant negative effect of classmates' prosocial behavior ( $p=$ .034), where a one-unit increase in classmates' prosocial behavior (on a scale from 0 to 10) coincided with a decrease in individual antisocial behavior of 0.428 (on a scale from 0 to 16). Hence, Hypothesis 1 was accepted. We also found a significant effect of T1 individual antisocial behavior on antisocial behavior at T3 $(p<.001)$, indicating that the more antisocial behavior an individual exhibited at T1, the more such behavior he or she exhibited at T3. No effect of classmates' antisocial behavior was found $(p=.602)$ and male gender was related to more antisocial behavior $(p<.001)$.

With regard to variance components, there was significant variation on the individual level (Level 1; $p<.001$ ) and on the classroom level (Level 2; $p<.001$ ). The intraclass correlation coefficient (ICC 1) indicated that $5.3 \%$ of the total variance was due to differences between classrooms. 
Hypothesis 2. Table 5 presents the results of the tests of Hypothesis 2. This hypothesis was based on the assumption that the effect of classmates' prosocial behavior on individual antisocial behavior was mediated by individual attitudes toward antisocial behavior. We first tested whether there is a direct effect of the predictor on the mediator and a direct effect of the mediator on the dependent variable.

Table 4

Multilevel Analyses for Classmates' Prosocial Behavior at T1 Predicting Individual Antisocial Behavior at T3

\begin{tabular}{|c|c|c|c|c|c|}
\hline & $B$ & $S E B$ & $z$ & $\beta$ & $p$ \\
\hline \multicolumn{6}{|l|}{ Fixed effects } \\
\hline $\begin{array}{l}\text { Classmates' prosocial } \\
\text { behavior } \mathrm{T} 1\end{array}$ & -0.428 & 0.202 & -2.125 & -.105 & .034 \\
\hline $\begin{array}{l}\text { Classmates' antisocial } \\
\text { behavior T1 }\end{array}$ & -0.068 & 0.130 & -0.522 & -0.024 & .602 \\
\hline $\begin{array}{l}\text { Individual antisocial } \\
\text { behavior } \mathrm{T} 1\end{array}$ & 0.531 & 0.058 & 9.209 & .500 & $<.001$ \\
\hline Male gender & 0.852 & 0.209 & 4.087 & .172 & $<.001$ \\
\hline Variance Components & & & & & \\
\hline $\begin{array}{l}\text { Level } 1 \\
\text { (within classrooms) }\end{array}$ & 4.232 & 0.446 & 9.488 & & $<.001$ \\
\hline $\begin{array}{l}\text { Level } 2 \\
\text { (between classrooms) }\end{array}$ & 0.346 & 0.098 & 3.539 & & $<.001$ \\
\hline ICC 1 Level 2 & 0.054 & & & & \\
\hline
\end{tabular}

Note. The ICC 1 on Level 2 was 0.049 in the intercept-only model (empty model without predictors; not shown in this table). 
The first model in Table 5 indicates the negative effect of classmates' prosocial behavior on individual antisocial attitudes is not significant $(p=.050)$. Hence, the first assumption of a direct effect of the predictor on the mediator was not fulfilled. In Model 2, individual attitudes were included as a predictor of individual antisocial behavior and revealed a significant positive effect $(p<.001)$. This finding indicates that more favorable attitudes toward antisocial behavior predicted more such behavior. Accordingly, less positive attitudes toward antisocial behavior predicted less antisocial behavior. However, as the first assumption of a mediation process was not met, an indirect effect would have been meaningless to test (Kenny \& Judd, 2014; Rucker et al., 2011). 
Table 5

Multilevel Analyses for the Indirect Effect of Classmates' Prosocial Behavior at T1 on Individual Antisocial Behavior at T3, Mediated by Individual Attitudes Toward Antisocial behavior at T2

\begin{tabular}{|c|c|c|c|c|c|c|c|c|c|c|}
\hline & \multicolumn{5}{|c|}{ Model 1: Prediction of individual attitudes } & \multicolumn{5}{|c|}{ Model 2: Prediction of individual behavior } \\
\hline & $B$ & $S E B$ & $z$ & $\beta$ & $p$ & $B$ & $S E B$ & $z$ & $\beta$ & $p$ \\
\hline \multicolumn{11}{|l|}{ Fixed effects } \\
\hline $\begin{array}{l}\text { Classmates' prosocial } \\
\text { behavior } \mathrm{T} 1\end{array}$ & -0.098 & 0.050 & -1.959 & -.100 & .050 & -0.366 & 0.215 & -1.701 & -.086 & .089 \\
\hline $\begin{array}{l}\text { Classmates' antisocial } \\
\text { behavior T1 }\end{array}$ & -0.014 & 0.030 & -0.456 & -0.021 & .648 & -0.048 & 0.136 & -0.351 & -0.017 & .726 \\
\hline $\begin{array}{l}\text { Individual antisocial } \\
\text { attitudes T2 }\end{array}$ & - & - & - & - & - & 0.808 & 0.187 & 4.318 & .188 & $<.001$ \\
\hline $\begin{array}{l}\text { Individual antisocial } \\
\text { behavior } \mathrm{T} 1\end{array}$ & 0.085 & 0.015 & 5.709 & .346 & $<.001$ & 0.468 & 0.063 & 7.400 & .445 & $<.001$ \\
\hline Male gender & 0.191 & 0.034 & 5.572 & .164 & $<.001$ & 0.691 & 0.206 & 3.354 & .138 & .001 \\
\hline \multicolumn{11}{|l|}{ Variance Components } \\
\hline $\begin{array}{l}\text { Level } 1 \\
\text { (within classrooms) }\end{array}$ & 0.281 & 0.031 & 9.082 & - & $<.001$ & 4.062 & 0.432 & 9.414 & - & $<.001$ \\
\hline $\begin{array}{l}\text { Level } 2 \\
\text { (between classrooms) }\end{array}$ & 0.009 & 0.005 & 2.015 & - & 0.044 & 0.331 & 0.093 & 3.542 & - & $<.001$ \\
\hline ICC 1 Level 2 & 0.028 & - & - & - & - & 0.052 & - & - & - & - \\
\hline
\end{tabular}




\section{Discussion}

The current study investigated the benefits of positive peer influence on adolescents' antisocial behavior development and its underlying mechanisms. We hypothesized that higher levels of prosocial behavior among classmates are associated with a lower likelihood that individuals in those classrooms exhibit antisocial behavior in the future. Furthermore, we assumed that individual attitudes toward antisocial behavior serve as a mediating factor in this process.

Regarding our first hypothesis, results indicated that more prosocial behavior among classmates predicted lower levels of individual antisocial behavior in the future. An influence of peers' prosocial behavior was found over and above the effect of peers' antisocial behaviors. To understand this result in context, it should first be noted that a strong predictor of future (T3) antisocial behavior was individual antisocial behavior at baseline (T1). Thus, independent of the peer characteristics, adolescents with higher initial levels of antisocial behavior tended to exhibit more such behavior in the future. Another significant individual predictor was gender, indicating a higher risk for future antisocial behaviors among boys than girls. Finally, antisocial behavior among all participants increased between Grade 7 and Grade 9, a finding that is in line with much of the adolescent development literature (e.g., Thornberry, 1987; Zhang, Loeber, \& StouthamerLoeber, 1997). It can thus be concluded that while adolescents generally developed more antisocial behavior over time, classmates' prosocial behavior decreased adolescents' individual likelihood of exhibiting future antisocial behavior.

Our finding extends Henry and colleagues' reports on the influence of classmates' prosocial injunctive norms on students' aggressive behavior (Henry \& Chan, 2010; Henry et al., 2011) in two ways. First, positive peer influence appears to relate not only to peer attitudes toward prosocial behaviors, but also to observable prosocial behaviors in the classroom. While peers' attitudes may often translate into individual behavior through communicative processes (e.g., classmates emphasize the importance of being friendly), the influence of peers' prosocial behavior may also include observation-based social learning processes. Second, prosocial peer behavior may not merely influence individual aggression but also a broader range of antisocial behaviors such as violating school or home rules, and 
delinquency. These types of behaviors may not be intended to harm others but often carry negative consequences for other people (for example, staying away from home may create trouble for parents). Hence, prosocial peer norms may thus contribute to a more general sensitivity to avoiding harm to others. However, as the current study used a sum score of different antisocial behaviors, further analyses in specific behavioral domains are needed.

To our knowledge, no study to date has investigated the mechanisms underlying positive peer influence on antisocial behaviors. Our data did not provide evidence that individual attitudes toward antisocial behavior serve as a mediator of classmates' positive influence. While individual attitudes were an important predictor of individual antisocial behavior (in line with the theory of planned behavior; Ajzen, 1991; Fishbein \& Ajzen, 1975), there was only a statistical tendency for an effect of classmates' prosocial behavior on individual attitudes toward antisocial behaviors. Given that the interactional theory of delinquency (Thornberry, 1987) generally suggests within-domain influences (e.g., peer antisocial behavior affects individual attitudes toward antisocial behavior), an explanation for our results may be that we investigated cross-domain influences. It could well be that classmates' prosocial behavior influences individual attitudes toward prosocial behavior, which then affect individual antisocial behavior. A more technical explanation for the nonsignificant finding might be the shared variance between classmates' prosocial and antisocial behaviors: Even though classmates' antisocial behavior was not a significant predictor in our models, it might still have reduced the explanatory power of classmates' prosocial behavior. As the effect of prosocial behavior on individual attitudes was close to significance, further investigation on the role of attitudes in positive peer influence appears to be warranted.

\section{Implications}

Although our findings are based on a correlative study design and do not allow causal conclusions, they still provide perspectives to inform the prevention of adolescent antisocial behavior. While in the context of antisocial behavior the peer group is often assumed a risk, our results indicate that school peers can also exert positive influence. As this study focused on the influence of behavior among all classmates and not just among 
personal friends, this result may be most informative for preventing antisocial behaviors using interventions in the classroom setting.

One effective way to reduce individual antisocial behaviors is to directly target students' individual competences and antisocial behaviors (e.g., by using principles of social problem-solving or applied behavior analysis; McMurran \&McGuire, 2005; Alberto

$\&$ Troutman, 2006). Our study results suggest that, in addition to focusing on the individual level, it may be useful to intervene on group descriptive norms at the classroom level. Hereby our finding of an effect of prosocial peer norms over and above antisocial peer norms suggests that building up prosocial behaviors in the classroom may be a promising approach for the prevention of antisocial behavior.

Evidence that promoting prosocial behavior can have a positive impact on individual antisocial behaviors is demonstrated by a pilot intervention study by Caprara and colleagues (2014): Students who participated in a school-wide intervention aimed at increasing individual prosocial behaviors and competences in middle school (using, e.g., sensitization to prosocial values and development of emotional regulation and perspectivetaking skills) had a lower likelihood of engaging in aggressive behaviors over time, compared to students in a control group. When considering this study in light of our current results, the decrease in individual aggressive behaviors may not only have occurred due to an individual increase in prosocial competence. Rather, fostering prosocial behaviors in classrooms may also have resulted in positive peer influence processes among the students. It is likely that prosocial classrooms will negatively sanction, or at least fail to reinforce, antisocial behaviors such that individual antisocial behavior in prosocial classrooms decreases.

\section{Strengths, Limitations, and Future Directions}

The results of this study add to the sparse knowledge on the positive side of peer influence on antisocial behaviors. A strength of the current investigation is that we could follow an almost complete cohort of students from a specific region across three school years. The local school system with self-contained classrooms and the relatively high 
classroom participation rates allowed us to systematically investigate peer influence by the classmates.

However, our study also had several limitations. First, we used self-reported data, which can be susceptible to social desirability bias. We tried to reduce this problem by using anonymous questionnaires, mobile blinds between participants, and the concept of perceived "coolness" of antisocial behaviors as an assessment of attitudes. Nevertheless, additional information would further improve the validity of our findings, such as peer or teacher ratings.

Second, a broad range of behaviors were represented in the measures of antisocial behavior and antisocial attitudes. In choosing our instruments, we opted for a compromise between assessing a very general construct (e.g., all types of externalizing behaviors) and a narrow perspective on single types of antisocial behaviors (e.g., alcohol consumption). After analyzing the broader construct of antisocial behavior, follow-up research could more specifically investigate different subtypes of antisocial behaviors, such as differential effects on students' direct and indirect aggressive acts.

Third, our measures of attitudes and of behaviors were not completely congruent with the theory of planned behavior (Ajzen, 1985, 1991). This theory suggests that correlations are highest when the exact same constructs are assessed usingattitudes and behavior measures (e.g., assessing attitudes toward alcohol consumption and actual consumption). While our study's assessments of attitudes and behaviors related to the same broader construct of antisocial behavior, items differed between the instruments. Using identical behavior descriptions might have resulted in higher correlations between adolescents' attitudes and behaviors, which would thus allow for an even closer match with the theory of planned behavior.

Given that this study did not find clear evidence for a mediation effect of antisocial attitudes, future studies should further investigate potential mechanisms underlying positive peer influence. This would increase understanding of the ways in which prosocial peer behavior serves as a preventive factor in the development of antisocial behavior. In addition, analyses of more complex and reciprocal influences between individual and 
classroom prosocial and antisocial behaviors and attitudes would add to the current knowledge.

Other interesting future directions for research include the role of gender in the investigated peer influence processes. As antisocial and prosocial behaviors may not have the same importance for social comparison among boys and girls (see e.g., Heimer, 1996), more detailed study of gender differences may be promising.

In sum, this study showed the positive potential of prosocial classroom norms for preventing antisocial behavior among adolescents. Our findings point to the importance of future research to shed additional light on the processes underlying positive peer influence and the practical implications it holds.

\section{References}

Achenbach, T. M. (1991). Manual of the Youth Self-Report and 1991 Profile. Burlington: University of Vermont, Department of Psychiatry.

Ajzen, I. (1985). From intentions to actions: A theory of planned behavior. In J. Kuhl \& J. Beckmann (Eds.), Action control: from cognition to behavior (pp. 11-39). Berlin: Springer.

Ajzen, I. (1991). The theory of planned behavior. Organizational Behavior and Human Decision Processes, 50, 179-211.

Akers, R. L. (2009). Social learning and social structure. A general theory of crime and deviance (2nd ed.). New Brunswick: Transaction Publishers.

Alberto, P. A. \& Troutman, A. C. (2006). Applied behavior analysis for teachers. Upper Saddle River: Pearson.

Aronson, E., Wilson, T. D., \& Akert, R. M. (2014). Social psychology (8th ed.). Essex: Pearson.

Bandura, A., \& Walters, R. H. (1963). Social learning and personality development. New York: Holt, Rinehart \& Winston.

Barth, J. M., Dunlap, S. T., Dane, H., Lochman, J. E., \& Wells, K. C. (2004). Classroom environment influences on aggression, peer relations, and academic focus. Journal of School Psychology, 42, 115-133. 
Batson, C. D., \& Powell, A. A. (2003). Altruism and prosocial behavior. In T. Millon \& M. J. Lerner (Eds.), Handbook of Psychology, Volume 5: Personality and Social Psychology (pp. 463-484). Hoboken, NJ: Wiley.

Boxer, P., Tisak, M. S., \& Goldstein, S. E. (2004). Is it bad to be good? An exploration of aggressive and prosocial behavior subtypes in adolescence. Journal of Youth and Adolescence, 33, 91-100.

Briñol, P., \& Petty, R. E. (2012). A history of attitudes and persuasion research. In A. W. Kruglanski \& W. Stroebe (Eds.), Handbook of the history of social psychology (pp. 283-320). New York: Tayler \& Francis Group.

Brown, B. B., Bakken, J. P., Ameringer, S. W., \& Mahon, S. D. (2008). A comprehensive conceptualisisation of the peer influence process in adolescence. In M. J. Prinstein \& K. A. Dodge (Eds.), Understanding peer influence in children and adolescent (pp. 1744). New York: Guilford.

Burgess, R., \& Akers, R. (1966). A differential association-reinforcement theory of criminal behavior. Social Problems, 14, 128-147.

Caprara, V. C., Luengo Kanacri, B. P., Gerbino, M., Zuffiano, A., Alessandri, G., Vecchio, G., Caprara, E., Pastorelli, C., \& Bridglall, B. (2014). Positive effects of promoting prosocial behavior in early adolescence: Evidence from a school-based intervention. International Journal of Behavioral Development, 38, 386-396.

Cialdini, R. B., Kallgren, C. A., \& Reno, R. R. (1991). A focus theory of normative conduct: A theoretical refinement and reevaluation of the role of norms in human behavior. Advances in Experimental Psychology, 24, 201-234.

Cohen, A. R. (1964). Attitude change and social influence. New York: Basic Books.

Cohn, E. S., Bucolo, D., Rebellon, C. J., \& Van Gundy, K. (2010). An integrated model of legal and moral reasoning and rule-violating behavior: The role of legal attitudes. Law and Human Behavior, 34, 295-309.

Dijkstra, J. K., Lindenberg, S., \&Veenstra, R. (2008). Beyond the class norm: Bullying behavior of popular adolescents and its relation to peer acceptance and rejection. Journal of Abnormal Child Psychology, 36, 1289-1299.

Dishion, T. J., \& Tipsord, J. M. (2011). Peer contagion in child and adolescent social and 
emotional development. Annual Review of Psychology, 62, 189-214.

Eagly, A. H., \& Chaiken, S. (1993). The psychology of attitudes. Fort Worth: Harcourt Brace Jovanovich College Publishers.

Farrell, A. D., Henry, D. B., Schoeny, M. E., Bettencourt, A., \& Tolan, P. H. (2010). Normative beliefs and self-efficacy for nonviolence as moderators of peer, school, and parental risk factors for aggression in early adolescence. Journal of Clinical Child and Adolescent Psychology, 39, 800-813.

Fishbein, M., \& Ajzen, I. (1975). Belief, attitude, intention and behavior. An introduction to theory and research. Reading: Addison-Wesley.

Ganzeboom, H. B. G., \& Treiman, D. J. (1996). Internationally comparable measures of occupational status for the 1988 International Standard Classification of Occupation. Social Science Research, 25, 201-239.

Goodman, R., Meltzer, H., \& Bailey, V. (1998). The Strengths and Difficulties Questionnaire: a pilot study on the validity of the self-report version. European Child \& Adolescent Psychiatry, 7, 125-130.

Halgunseth, L. C., Perkins, D. F., Lippold, M. A., \& Nix, R. L. (2013). Delinquent-oriented attitudes mediate the relation between parental inconsistent discipline and early adolescent behavior. Journal of Family Psychology, 27, 293-302.

Hampel, P., \& Petermann, F. (2005). Screening psychischer Störungen im Jugendalter [Screening of psychological disorders in adolescents]. Bern: Huber.

Heimer, K. (1996). Gender, interaction, and delinquency: Testing a theory of differential social control. Social Psychology Quarterly, 59, 39-61.

Henry, D., \& Chan, W. (2010). Cross-sectional and longitudinal effects of sixth-grade setting-level norms for nonviolent problem solving on aggression and associated attitudes. Journal of Community Psychology, 38, 1007-1022.

Henry, D., Farrell, A. D., Schoeny, M. E., Tolan, P. H., \& Dymnicki, A. B. (2011). Influence of school-level variables on aggression and associated attitudes of middle school students. Journal of School Psychology, 49, 481-503.

Henry, D., Guerra, N., Huesmann, R., Tolan, P., VanAcker, R., \& Eron, L. (2000). Normative influences on aggression in urban elementary school classrooms. American 
Journal of Community Psychology, 28, 59-81.

Hoglund, W. L., \& Leadbeater, B. J. (2004). The effects of family, school, and classroom ecologies on changes in children's social competence and emotional and behavioral problems in first grade. Developmental Psychology, 40, 533-544.

Jonkmann, K., Trautwein, U., \& Lüdtke, O. (2009). Social dominance in adolescence: The moderating role of the classroom context and behavioral heterogeneity. Child Development, 80, 338-355.

Juvonen, J., \& Galván, A. (2008). Peer influence in involuntary social groups. Lessons from research on bullying. In M. J. Prinstein \& K. A. Dodge (Eds.), Understanding peer influence in children and adolescents (pp. 225-244). New York: Guilford.

Kenny, D. A., \& Judd, C. M. (2014). Power anomalies in testing mediation. Psychological Science, 25, 334-339.

Kiesner, J., Poulin, F., \& Nicotra, E. (2003). Peer relations across contexts: Individualnetwork homophily and network inclusion in and after school. Child Development, 74, 1328-1343.

Klasen, H., Woerner, W., Rothenberger, A., \& Goodman, R. (2003). Die deutsche Fassung des Strengths and Difficulties Questionnaire (SDQ-Deu)--Übersicht und Bewertung erster Validierungs-und Normierungsbefunde [The German version of the Strengths and Difficulties Questionnaire (SDQ-Deu) - Overview over first validation and normative studies]. Praxis Der Kinderpsychologie Und Kinderpsychiatrie, 52, 491502.

Loeber, R. (1985). Patterns and development of antisocial child behavior. In G. J. Whitehurst (Ed.), Annals of child development (Vol. 2, pp. 77-116). Greenwich: Routledge.

McMurran, M. \&McGuire, J. (Eds.) (2005). Social problem solving and offending: Evidence, evaluation and evolution. Chichester: Wiley.

Mears, D., Ploeger, M., \& Warr, M. (1998). Explaining the gender gap in delinquency: Peer influence and moral evaluations of behavior. Journal of Research in Crime and Delinquency, 35, 251-266 
Megens, K. C. I. M., \&Weerman, F. M. (2011). The Social Transmission of Delinquency: Effects of Peer Attitudes and Behavior Revisited. Journal of Research in Crime and Delinquency, 49, 420-443.

Mercer, S. H., McMillen, J. S., \& DeRosier, M. E. (2009). Predicting change in children's aggression and victimization using classroom-level descriptive norms of aggression and pro-social behavior. Journal of School Psychology, 47, 267-289.

Mercken, L., Snijders, T. A. B., Steglich, C., Vertiainen, E., \& De Vries, H. (2010). Smoking-based selection and influence in gender-segregated friendship networks: A social network analysis of adolescent smoking. Addiction, 105, 1280-1289.

Monahan, K. C., Steinberg, L., Cauffman, E., \& Mulvey, E. P. (2009). Trajectories of antisocial behavior and psychosocial maturity from adolescence to young adulthood. Developmental Psychology, 45, 1654-1668.

Müller, C. M. (2013). Dissoziale Verhaltensweisen und Einstellungen im Längsschnitt erfassen - Entwicklung und Evaluation der "Freiburger Selbst- und Peerauskunftsskalen - Dissozialität" [Assessing antisocial behavior and attitudes in longitudinal research - Development and evaluation of the "Fribourg Self- and PeerReport Scales - Antisocial Behavior"]. Heilpädagogische Forschung, 39, 2-13.

Muthén, L. K., \& Muthén, B. O. (2015). Mplus User's Guide (7th ed.). Los Angeles: Muthén \& Muthén.

Parsai, M., Voisine, S., \&Marsiglia, F. (2009). The protective and risk effects of parents and peers on substance use, attitudes, and behaviors of Mexican and Mexican American female and male adolescents. Youth \& Society, 40, 353-376.

Powers, C. J., \& Bierman, K. L. (2013). The multifaceted impact of peer relations on aggressive-disruptive behavior in early elementary school. Developmental Psychology, 49, 1174-1186.

Quinn, M. M., \& Poirier, J. M. (2004). Linking prevention research with policy. Examining the costs and outcomes of the failure to prevent emotional and behavioral disorders. In R. B. Rutherford, Q. M. M., \& S. R. Mathur (Eds.), Handbook of research in emotional and behavior disorders (pp. 78-97). New York: Guilford.

Raudenbush, S., \& Bryk, A. (2002). Hierarchical linear models: Applications and data 
analysis methods (2nd ed.). Thousand Oaks: Sage.

Reynolds, W. M. (2001). Reynolds Adolescent Adjustment Screening Inventory (RAASI). Odessa, FL: Psychological Assessment Resources.

Rose, B. M., Holmbeck, G. N., Coakley, R. M., \& Franks, E. A. (2004). Mediator and moderator effects in developmental and behavioral pediatric research. Journal of Developmental and Behavioral Pediatrics, 25, 58-67

Rucker, D. D., Preacher, K. J., Tormala, Z. L., \& Petty, R. E. (2011). Mediation analysis in social psychology: Current practices and new recommendations. Social and Personality Psychology Compass, 5, 359-371.

Schulenberg, J., Maggs, J. L., Dielman, T. E., Leech, S. L., Kloska, D. D., Shope, J. T., \& Laetz, V. B. (1999). On peer influences to get drunk: A panel study of young adolescents. Merrill-Palmer Quarterly, 45, 108-142.

Shaffer, L. S. (1983). Toward Pepitone's vision of a normative social psychology: What is a social norm? Journal of Mind and Behavior, 4, 275-294.

Simcha-Fagan, O., Langner, T. S., Gersten, J. C., \& Eisenberg, J. (1975). Violent and antisocial behavior: A longitudinal study. Washington, DC: National Institute of Education, Office of Child Development.

Thornberry, T. P. (1987). Toward an interactional theory of delinquency. Criminology, 25, 863-892.

Urben, S., Habersaat, S., Suter, M., Pihet, S., De Ridder, J., \&Stéphan, P. (2016). Gender differences in at risk versus offender adolescents: A dimensional approach of antisocial behavior. Psychiatric Quarterly, 87, 619-631.

Vanhove, J. (2015). Analyzing randomized controlled interventions: Three notes for applied linguists. Studies in Second Language Learning and Teaching, 5, 135-152.

Veenstra, R. (2006). The development of Dr. Jekyll and Mr. Hyde: Prosocial and antisocial behavior in adolescence. In D. Fetchenhauer, A. Flache, B. Buunk, \& S. Lindenberg (Eds.), Solidarity and Prosocial Behavior: An Integration of Sociological and Psychological Perspectives (pp. 93-108).

Vellacott, M. C., Hollenweger, J., Nicolet, M., \& Wolter, S. C. (2003). Soziale Integration und Leistungsförderung. Thematischer Bericht der Erhebung PISA 2000 [Social 
integration and promotion. Thematic report of the PISA 2000 survey].

Vitaro, F., Brendgen, M., \& Tremblay, R. E. (2000). Influence of deviant friends on delinquency: Searching for moderator variables. Journal of Abnormal Child Psychology, 28, 313-325.

Zhang, Q., Loeber, R., \& Stouthamer-Loeber, M. (1997). Developmental trends of delinquent attitudes and behaviors: Replications and synthesis across domains, time, and samples. Journal of Quantitative Criminology, 13, 181-215.

This research was supported by the Swiss National Science Foundation (SNF-143459 and SNF-166024) 